\title{
Erythropoiesis-Stimulating Agents (ESA) for Preventing the Progression of Chronic Kidney Disease: A Meta-Analysis of 19 Studies
}

\author{
Adrian Covic $^{a}$ Ionut Nistor ${ }^{a}$ Mihaela-Dora Donciu $^{a}$ Raluca Dumea ${ }^{a}$ \\ Davide Bolignano $^{\mathrm{b}}$ David Goldsmith ${ }^{\mathrm{c}}$ \\ ${ }^{a}$ Nephrology Department, Faculty of Medicine, University of Medicine and Pharmacy 'Gr. T. Popa', lasi, Romania; \\ ${ }^{b}$ CNR-Institute of Clinical Physiology, Reggio Calabria, Italy; ' Renal Unit, Guy's and St. Thomas' NHS Foundation \\ Hospital, King's Health Partners, London, UK
}

\section{Key Words}

Chronic kidney disease $\cdot$ Anemia .

Erythropoiesis-stimulating agents · ESA .

CKD-progression · Meta-analysis · Systematic review

\begin{abstract}
Background: The effect of anemia correction on kidney function in chronic kidney disease (CKD) patients remains unclear. As $19-40 \%$ of patients with CKD receive an erythropoiesis-stimulating agent (ESA), this is a potentially important consideration. Summary: We conducted a systematic review and meta-analysis of randomized trials to January 1 , 2014 in adult patients with CKD stages 1 to 4 . Selection criteria for studies: randomized controlled trials of at least 2 months duration. Patients were allocated to ESA versus placebo, no treatment, or different ESA doses with the purpose of achieving a higher versus a lower hemoglobin target. The analyzed outcomes were the need for renal replacement therapy, doubling of serum creatinine, change in GFR $(\mathrm{ml} / \mathrm{min})$, mortality and withdrawal of treatment due to adverse events. A total of 19 trials ( $n=8,129$ participants with CKD stage 1-4) were reviewed. There was no difference in the risk of end-stage kidney disease (RR, 0.97 [Cl 0.83-1.20], 17 trials, 8,104 participants), change in GFR (Mean Difference [MD] $-0.45[-2.21,1.31], 9$ trials, 1,848 participants) or with-
\end{abstract}

drawal of treatment due to adverse events (RR, 1.18 [Cl 0.771.81], 10 trials, $n=1,958$ participants) for patients at higher hemoglobin $(\mathrm{Hb})$ targets. Furthermore, no statistically significant differences in mortality (Risk Ratio [RR] 1.10 [Cl 0.901.35], 16 trials, $\mathrm{n}=8,082$ participants) were observed. Key Messages: There is no evidence that ESA treatment affects renal function in patients with CKD. Use of these agents should not therefore be influenced by considerations about influencing CKD progression.

(c) 2014 S. Karger AG, Basel

\section{Introduction}

Chronic kidney disease (CKD) is a worldwide health burden, affecting about $10-15 \%$ of the Western adult population [1]. It is associated with premature death, cardiovascular disease, infection and cancer; it also consumes many valuable healthcare resources [2-5]. Prevention of CKD progression therefore is pivotal. Control of blood pressure (BP) by blockade of the renin-angiotensin-aldosterone system (RAAS) is the cornerstone of current CKD preventive treatment, delaying both cardiovascular and renal disease progression [6,7]. Alternative nephroprotective therapies have yet uncertain values (statins, pentoxyphillin, bicarbonate) [8]. Despite the

\section{KARGER}

E-Mail karger@karger.com

www.karger.com/ajn
(C) 2014 S. Karger AG, Basel

0250-8095/14/0403-0263\$39.50/0
Dr. Ionut Nistor

University of Medicine and Pharmacy 'Gr. T. Popa' Nephrology Department, Faculty of Medicine

University Street no 16, RO-700115 Iasi (Romania)

E-Mail ionutni@yahoo.com 
currently available therapy, CKD patients remain at a highly increased risk for progression toward end-stage renal disease and concomitant cardiovascular complications [9].

The effect of anemia correction on kidney function and progressive GFR loss is an under-researched topic. In this regard, the available literature is contradictory, with some researchers suggesting that correction of anemia with ESAs is beneficial for preventing further renal functional decline, while others suggest potential detrimental effects $[10,11]$.

Recently, comprehensive meta-analysis focusing on the impact of anemia treatment on mortality and cardiovascular impacts of anemia treatment was published [12]. They did not, however, focus on or report conclusive information on the impact of anemia treatment on renal function over time. Since some recent studies [13-15] have suggested that anemia treatment has a beneficial impact on renal function, we decided to perform a systematic analysis of the existing literature in order to establish if different degrees of anemia correction (low or high $\mathrm{Hb}$ targets) by ESAs may have different impact on renal function trajectories in CKD patients.

\section{Methods}

The systematic review and meta-analysis was performed according to a previously published protocol (http://www.crd.york. ac.uk/PROSPERO/display_record.asp?ID = CRD42014007162).

We searched MEDLINE (January 1966 to 1st of January 2014) and the Cochrane Controlled Clinical Trials Register Database (through Issue 1 of 12, January 2014); we also hand searched reference lists of textbooks, articles, and scientific proceedings for relevant articles (online suppl. table 1; for all online suppl. material, see www.karger.com/doi/10.1159/000366025).

We included all RCTs and quasi-RCTs with a study period of at least 2 months duration and assessed the effects of different hemoglobin $(\mathrm{Hb})$ targets in pre-dialysis patients with anemia of CKD on the prevention of the progression of CKD. The first period of randomized crossover studies was also considered for inclusion. There was no language restriction. The higher $\mathrm{Hb}$ target could be achieved by EPO ( $\alpha$ or $\beta$ ) or darbepoetin; the lower target could be achieved by lower doses of the same drugs or by a placebo or no treatment or blood transfusion.

Studies enrolling any patient with CKD stages 1-4 (as defined by the Kidney-Disease Outcomes and Quality Initiative [K-DOQI] guidelines: stage $1=\mathrm{GFR} \geq 90 \mathrm{ml} / \mathrm{min} / 1.73 \mathrm{~m}^{2}$; stage $2=\mathrm{GFR} 60$ $89 \mathrm{ml} / \mathrm{min} / 1.73 \mathrm{~m}^{2}$; stage $3=$ GFR $30-59 \mathrm{ml} / \mathrm{min} / 1.73 \mathrm{~m}^{2}$; stage $4=$ GFR $15-29 \mathrm{ml} / \mathrm{min} / 1.73 \mathrm{~m}^{2}$; stage $5=\mathrm{GFR}<15 \mathrm{ml} / \mathrm{min} / 1.73 \mathrm{~m}^{2}$ not requiring dialysis) were included. We excluded studies enrolling patients with CKD stage $5\left(\mathrm{GFR}<15 \mathrm{ml} / \mathrm{min} / 1.73 \mathrm{~m}^{2}\right)$ and who were receiving hemodialysis or other forms of dialysis including peritoneal dialysis. We also included studies on kidney transplanted patients if participants had residual GFR $>15 \mathrm{ml} / \mathrm{min} / 1.73 \mathrm{~m}^{2}$.
Data on the effects of ESAs on the following outcome measures were analyzed:

(1) Primary outcome:

(a) Need for renal replacement therapy (RRT);

(2) Secondary outcomes:

(b) Doubling of serum creatinine;

(c) A composite outcome - death or need for RRT (whichever came first) - since numerous authors [16] argue that the main outcome for CKD is in fact death $[17,18]$, and only 'CKD survivors' reach dialysis - in order to verify the previous result.

(d) Renal function measured as end-of-treatment GFR (ml/ $\min$ or $\mathrm{ml} / \mathrm{min} / 1.73 \mathrm{~m}^{2}$ ) and serum creatinine value at the end of the study ( $\mathrm{mg} / \mathrm{dl}$ or $\mu \mathrm{mol} / \mathrm{l})$; change in GFR $(\mathrm{ml} / \mathrm{min})$;

(e) End-of-treatment BP - systolic BP and diastolic BP (mm $\mathrm{Hg})$;

(f) Adverse events - (cardiovascular events, myocardial infarction and stroke, or any other serious adverse events as defined by the authors of the included studies);

(g) End-of-treatment urinary albumin/protein excretion $(24 \mathrm{~h}$ proteinuria or $24 \mathrm{~h}$ albuminuria in $\mathrm{g} / \mathrm{dl}$ );

(h) All-cause or cardiovascular-mortality (online suppl. fig. 5).

Data extraction was carried out independently by the reviewers, using standard data extraction forms. It was planned that studies reported in non-English language journals would be translated before assessment. It was also planned that where more than one publication of one trial existed, reports would be grouped and the most recent or complete dataset would be used. Disagreements between reviewers were resolved in consultation with AC.

The quality of included studies was assessed independently by (IN) and (DG) without blinding to authorship or journal according to recommendations from the Cochrane Collaboration [19]. The quality items assessed were selection bias (random sequence generation, allocation concealment), performance bias (blinding of patients and investigators), detection bias (blinding of outcome assessors), attrition bias (incomplete outcome data), reporting bias (selective reporting) and other forms of bias (significant different group comparisons, funding sources, early termination of a trial). We considered the RCT to be at a high risk of selective outcome reporting when investigators did not report data for all-cause mortality, need for renal replacement therapy, doubling of serum creatinine and adverse events or patient symptoms.

For dichotomous outcomes (all-cause mortality, number of patients starting RRT), the results were expressed as relative risks (RR) with $95 \%$ confidence intervals (CI). Data were pooled using a random-effects model, but the fixed-effects model was also analyzed to ensure robustness of the model chosen and susceptibility to outliers. Where continuous scales of measurement were used to assess the effects of treatment (serum creatinine value at the end of the study, GFR, BP), the mean differences and its 95\% CI were used.

Heterogeneity was analyzed with a chi-squared test on N-1 degrees of freedom, with an alpha of 0.05 used for statistical significance and with the $\mathrm{I}^{2}$ test $[20,21]$. An $\mathrm{I}^{2}$ value of $>50 \%$ indicates statistically large heterogeneity among the included studies. If substantial statistical heterogeneity were noted $\left(\mathrm{I}^{2}>50 \%\right)$, we planned to explore individual study characteristics and those of subgroups of the main body of evidence. Plausible reasons for variations in treatment effect (heterogeneity) were explored using subgroup analysis specifically for the length of follow-up, and type of ESA used and number of participants. All analyses were performed using Revman $5.1\left(^{(}\right) 2011$, The Cochrane Collaboration, UK). 
Fig. 1. Flowchart showing the number of citations retrieved by individual searches and number of trials included in the systematic review.
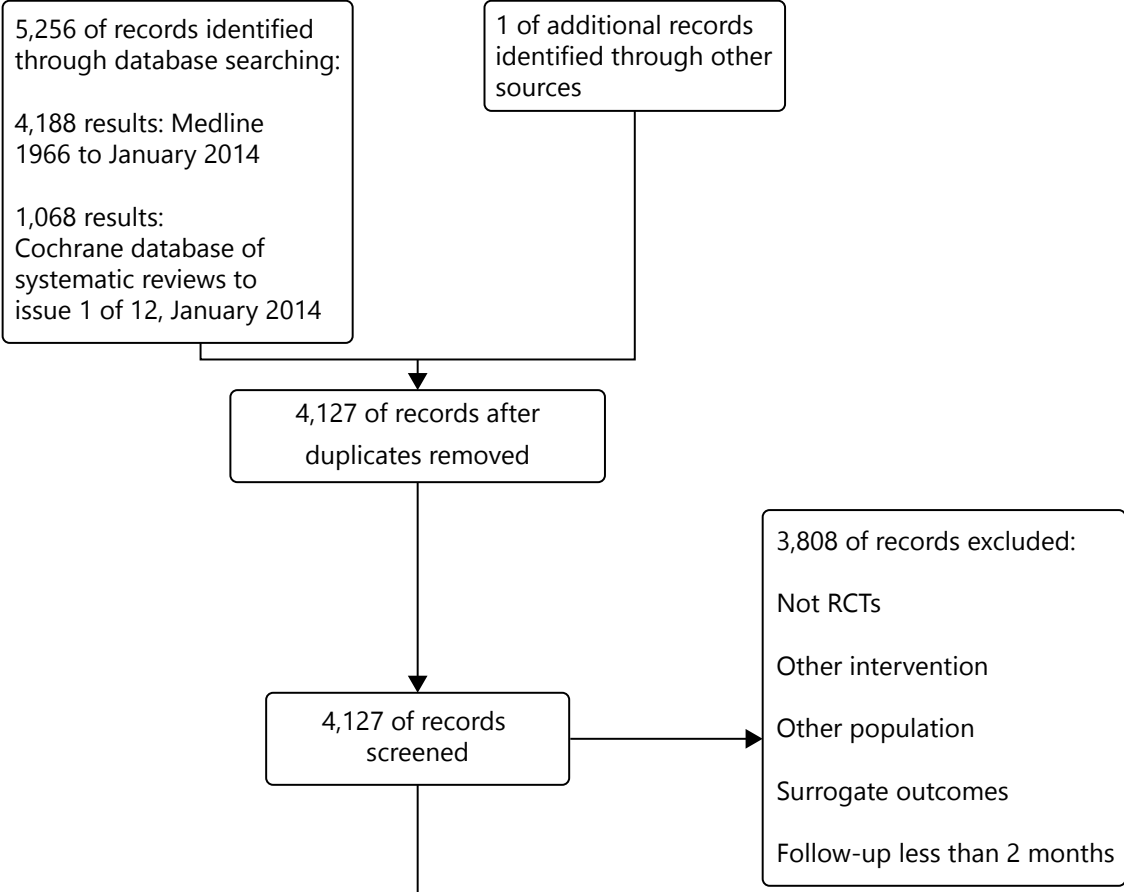

300 of full-text articles excluded with reasons:

108 full-text articles excluded non-RCT;

40 full-text articles excluded non-relevant outcome;

94 full-text articles excluded not appropriate intervention;

58 full-text articles excluded for being duplicates.

\section{Results}

\section{Search Results}

The combined search of MEDLINE, CENTRAL databases, and hand search by experts identified 5,257 citations, of which 3,808 were excluded (non-RCTs or studies evaluating other interventions not relevant to this review). Full-text assessment of 319 potentially relevant articles resulted in the identification of 19 eligible trials enrolling a total of 8,129 patients $[10,11,13-15,22-35]$ (fig. 1).

\section{Characteristics of the Included Studies}

Baseline studies characteristics are presented in table 1 . The population sample sizes varied between 88 and 4,038 patients $[10,35]$. Study duration ranged from twelve weeks [22-24], to 3.3 years [30]. The mean of the Glomerular filtration rate at the trial outsets spanned from 16 to $51 \mathrm{ml} / \mathrm{min} 1.73 \mathrm{~m}^{2}$. Baseline albuminuria/proteinuria ranged from 0.5 to $3.1 \mathrm{~g} /$ day. Only two studies did not include patients with diabetes mellitus [10,24]. One study included only renal transplant recipients [15]. 


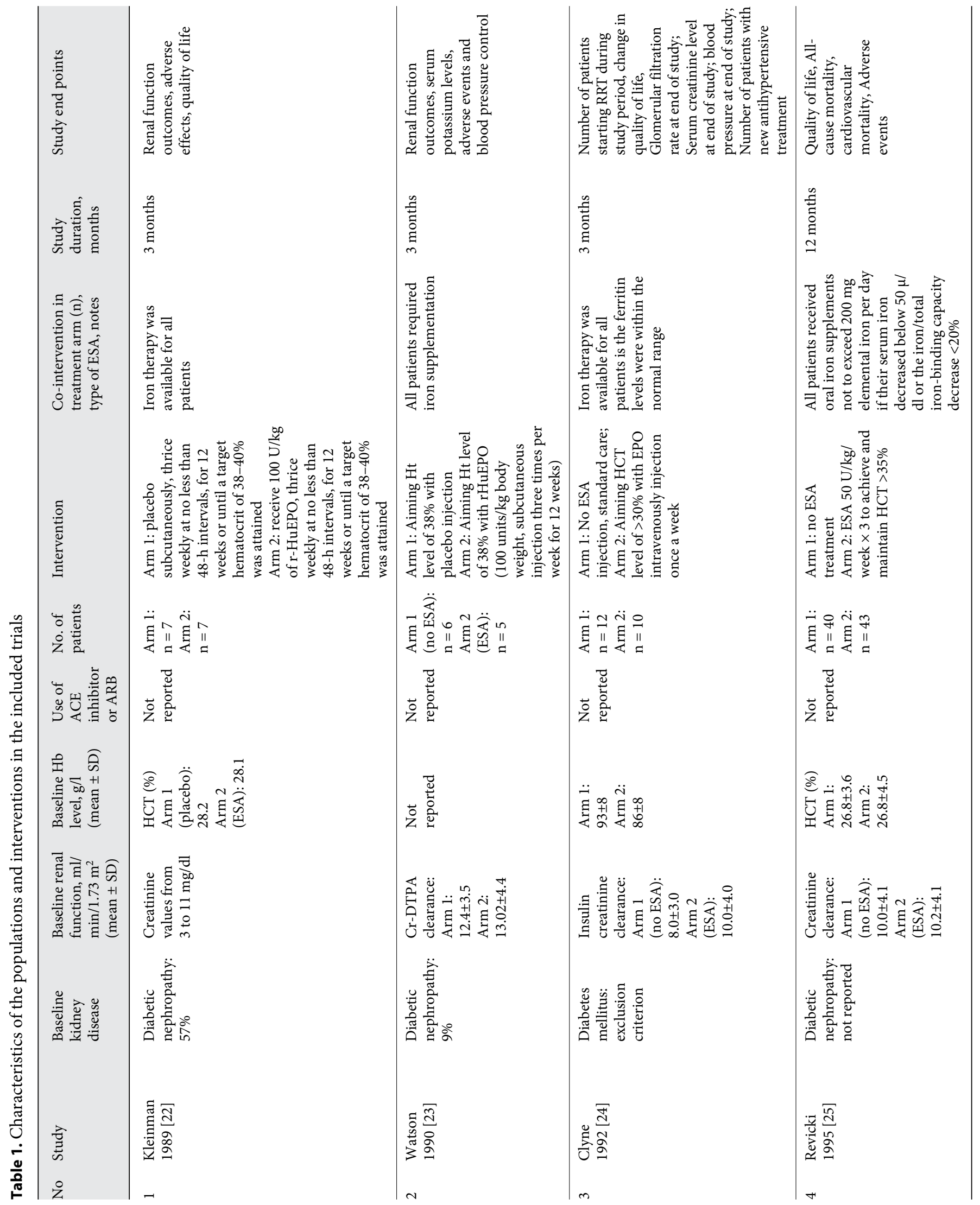




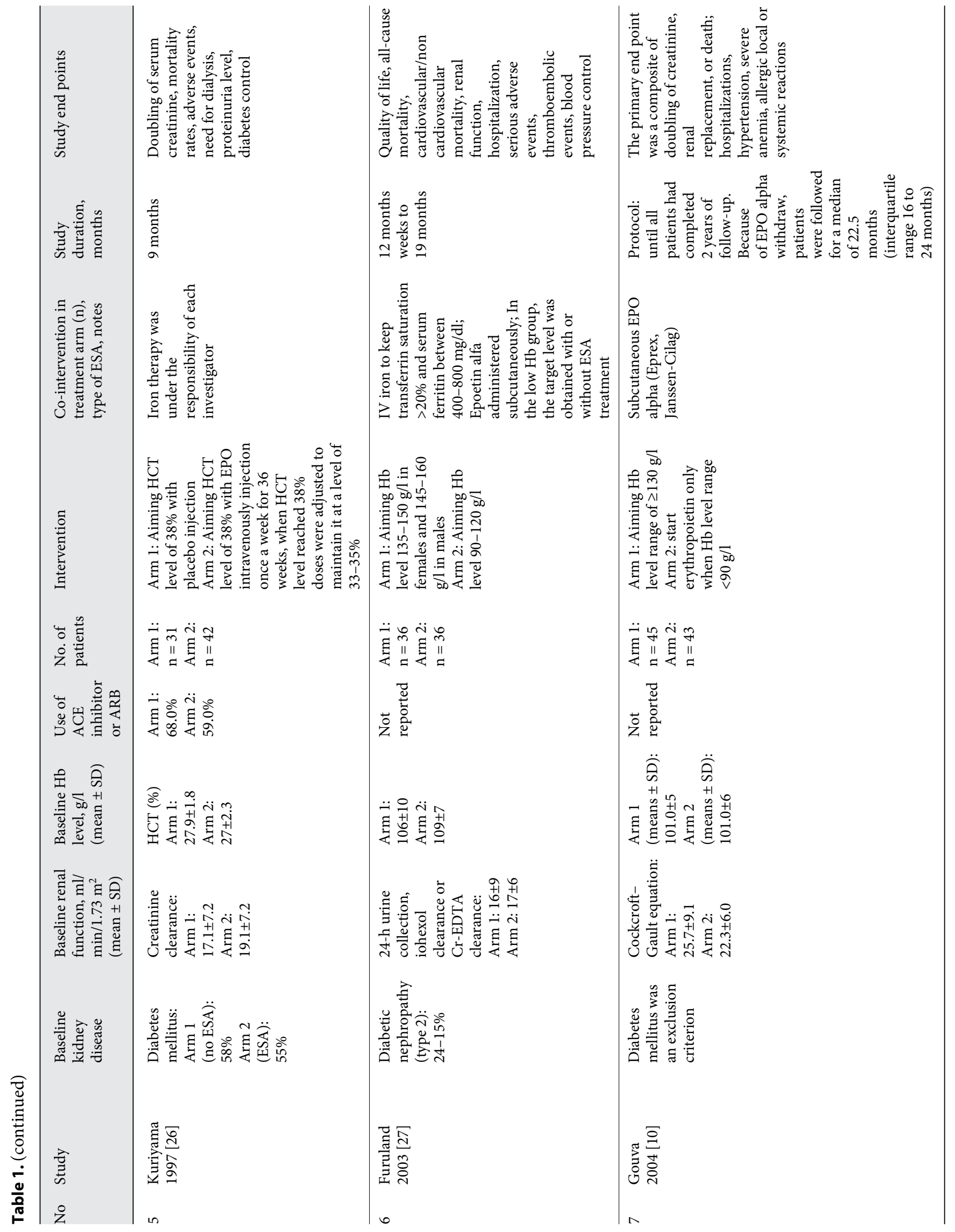




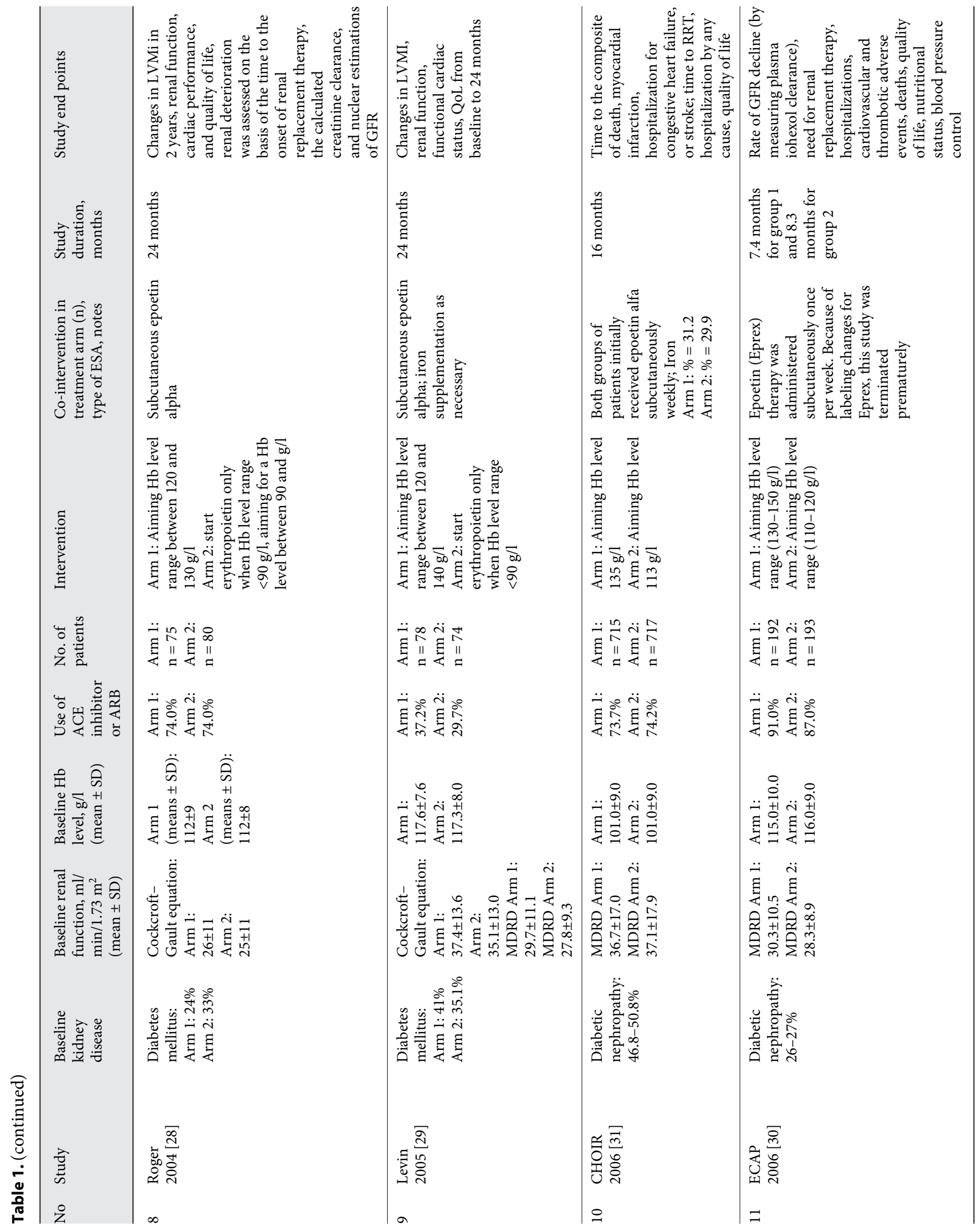




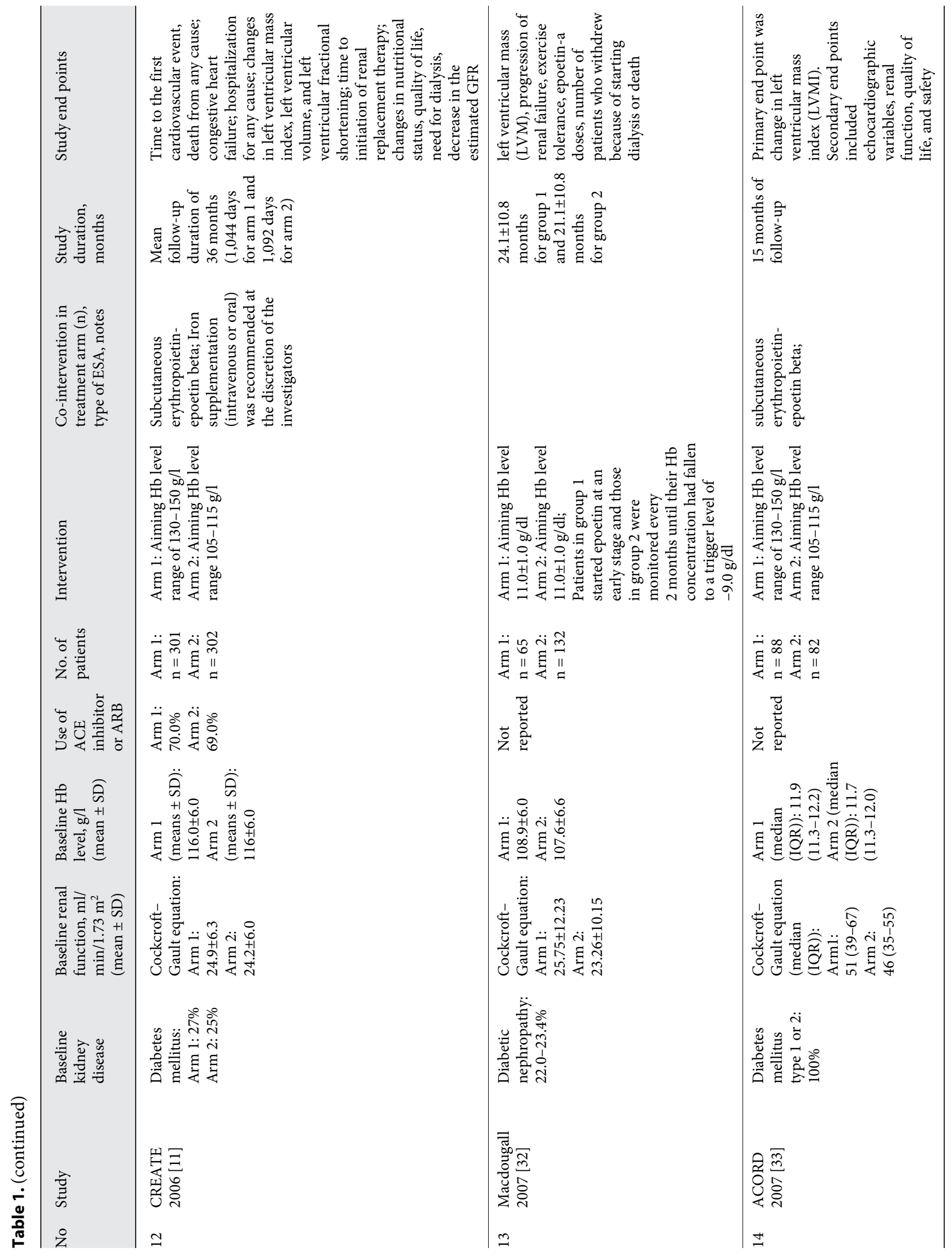




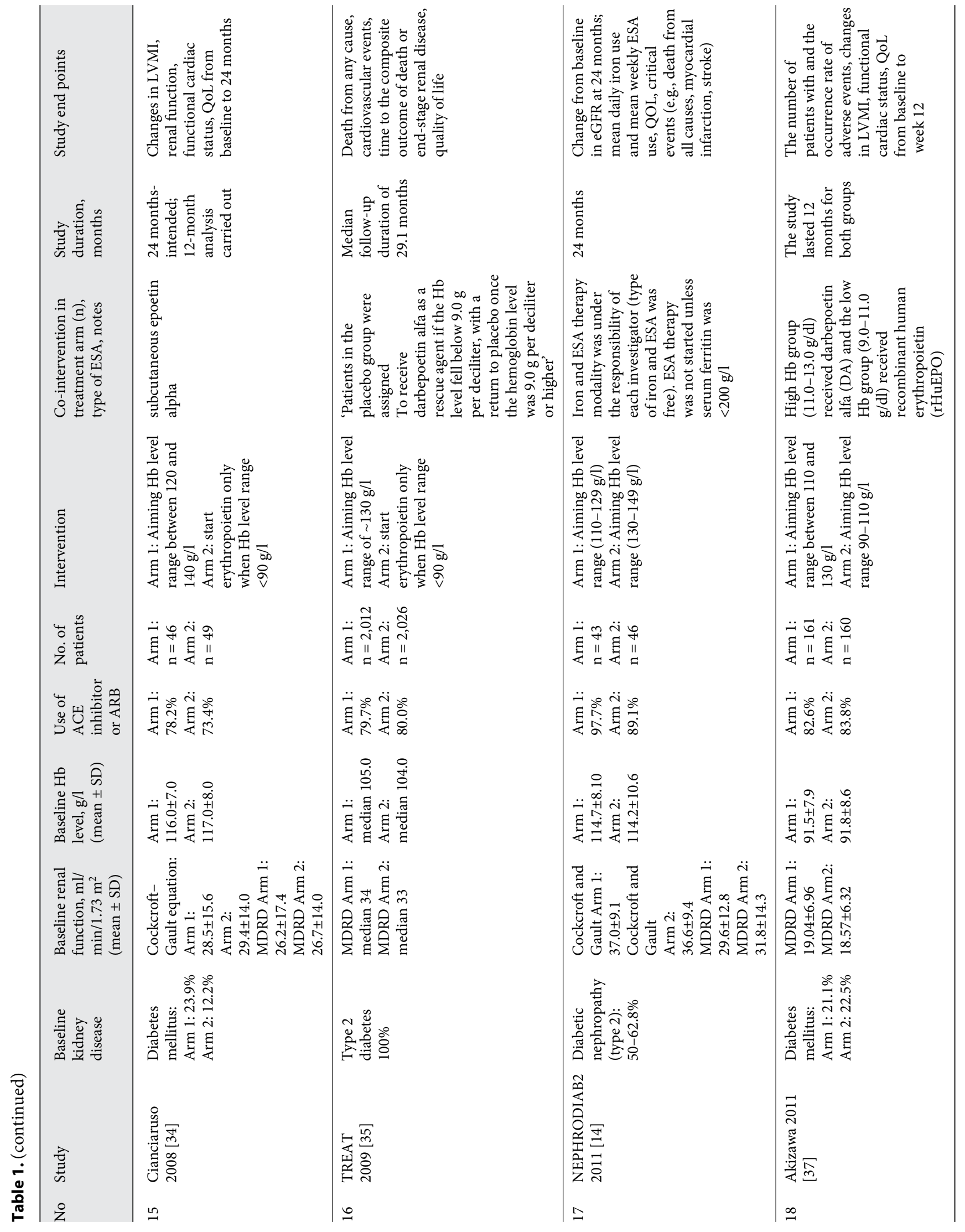




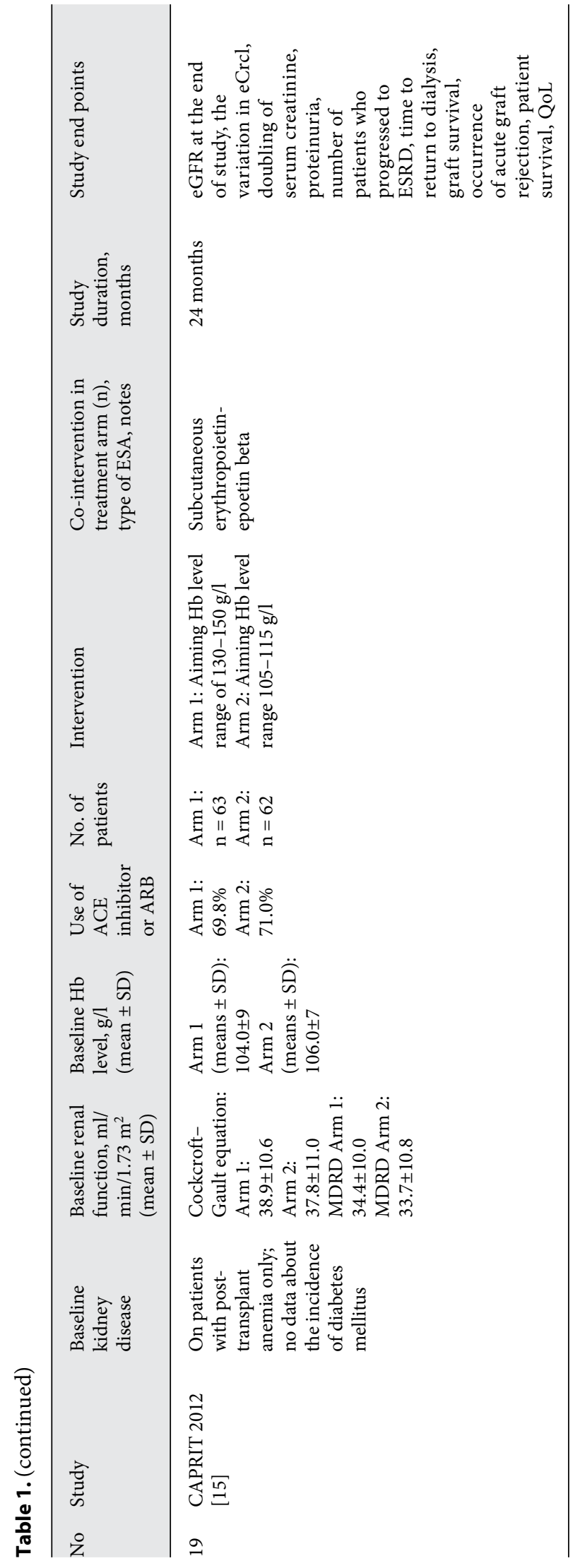

Four studies reported the decline in renal function or progression of renal disease as the primary endpoint $[10$, $14,15,26]$. Only one study reported early termination due to safety issues [30].

Baseline Hb levels varied from $9.0[10,27]$ to $12.9 \mathrm{~g} /$ dl [14]. In trials performed earlier (between 1990 and 2005), there was a trend toward a higher Hb target level (in the intervention group the upper $\mathrm{Hb}$ level limit was $15.0 \mathrm{~g} / \mathrm{dl}[11,27,30,33])$. After 2006, the anemia guideline committee of the KDOQI raised the suggested $\mathrm{Hb}$ cut-offs to $11.0 \mathrm{~g} / \mathrm{dl}$ for the lower limit (evidence-based recommendation) and $13.0 \mathrm{~g} / \mathrm{dl}$ for the upper limit (clinical practice recommendation) [36]. Following these guideline modifications, the more recent trials referred to a lower limit for the high $\mathrm{Hb}$ target $(13 \mathrm{~g} / \mathrm{dl}$ [35], $13.5 \mathrm{~g} / \mathrm{dl}$ [13]), with two notable exceptions: 14.9 $\mathrm{g} / \mathrm{dl}$ [14] and $15 \mathrm{~g} / \mathrm{dl}$ [15].

The treatment comparisons in the identified trials were: (a) ESA versus placebo or no treatment or, (b) different doses of ESA therapy as needed to achieve two (higher vs. lower) hemoglobin target levels. Doses of ESA used in the trials were not available in one third of the study reports (table 2).

As for the type of ESA, Erythropoietin alpha was used in eight trials [10,27-32,34], erythropoietin beta in three $[11,15,33]$ and darbepoetin alpha in two studies $[35,37]$. In old studies, the type of ESA was not specified [14, 22$24,26]$.

In the control arm, different treatment strategies were used. Treatment comparisons included different types of ESA versus placebo or no treatment unless $\mathrm{Hb}$ levels decreased below a specified value $[10,11,22-24$, $26,28-30,32-35]$, or different doses of ESA [14, 15, 31, 37].

\section{Trial Quality}

Trial quality was sub-optimal on overall. Allocation concealment was adequate in three of 19 trials (16\%) [29, 32,34 ] and unclear in the remaining 10 out of 19 trials (85\%). A consistent high risk of bias concerning the blinding of participants and personnel was found for the majority of included studies, with exception of one, in which the investigators stated the 'double-blinded' design of the trial, but without providing any additional information [23] and two studies with low risk of bias [22, 35]. Only three of the 19 trials $(16 \%)$ were analyzed on an intentionto-treat basis $[11,35,37]$. The dropout rate ranged from 0 to $15 \%$ and did not differ between the treatment and control groups (fig. 2). 
Table 2. Baseline, target and achieved hemoglobin concentrations for the included studies

\begin{tabular}{|c|c|c|c|c|c|}
\hline \multirow[t]{2}{*}{ Study } & \multirow{2}{*}{$\begin{array}{l}\text { Baseline Hgb } \\
\text { concentration, g/dl }\end{array}$} & \multicolumn{2}{|c|}{ Target Hgb concentration, g/dl } & \multicolumn{2}{|c|}{ Achieved Hgb concentration, g/dl } \\
\hline & & high/active group & low/no treatment & high/active group & low/no treatment \\
\hline Kleinman et al., 1989 [22] & HCT of $28.2 \%$ & HCT of $38-40 \%$ & HCT of $38-40 \%$ & HCT of $35.8 \%$ & HCT of $28.3 \%$ \\
\hline Watson et al., 1990 [23] & HCT of $28 \pm 2 \%$ & HCT of $38 \%$ & No target & HCT of $35 \pm 2 \%$ & HCT of $26 \pm 2 \%$ \\
\hline Clyne et al., 1992 [24] & $8.6 \pm 0.8$ & HCT of $>30 \%$ & No target & $11.7 \pm 1.1$ & $9.4 \pm 1.0$ \\
\hline Revicki et al., 1995 [25] & HCT of $26.8 \pm 3.6 \%$ & HCT of $35 \%$ & No target & Not reported & $8.9 \pm 1.2$ \\
\hline Kuriyama et al., 1997 [26] & HCT of $27.9 \pm 1.8 \%$ & HCT of $33-35 \%$ & $\mathrm{HCT}<30 \%$ & $11.83 \pm 1.33$ & $8.43 \pm 0.63$ \\
\hline Furuland et al., 2003 [27] & $10.6 \pm 1$ & $13.0-15.0$ & $9.0-12.0$ & $14.3 \pm 1.1$ & $11.3 \pm 1.3$ \\
\hline Gouva et al., 2004 [10] & $9.0-11.6$ & $\geq 13.0$ & Unless $\mathrm{Hb}<9.0$ & $\geq 12.5$ & $\geq 12.5$ \\
\hline Roger et al., 2004 [28] & $11.0-13.0$ to $10.0-12.0$ & $12.0-13.0$ & $\begin{array}{l}\text { Unless } \mathrm{Hb}<9.0 \text { at } 2 \\
\text { consecutive clinic visits } \\
\text { or } \mathrm{Hb}<8.0 \text { at any visit }\end{array}$ & $12.2 \pm 0.7$ & $11.0 \pm 1.0$ \\
\hline Levin et al., 2005 [29] & $11.0-13.5$ & $12.0-14.0 \pm 0.5$ but not $>14$ & Unless $\mathrm{Hb}<9$ & Not reported & $11.4 \pm 1.2$ \\
\hline CHOIR 2006 [31] & $<11.0$ & 13.5 & 11.3 & Not reported & Not reported \\
\hline ECAP 2006 [30] & $\begin{array}{l}\text { Men: }<13.0 \\
\text { Women: }<12.5\end{array}$ & $13.0-15.0$ & $11.0-12.0$ & 16.2 & 16.1 \\
\hline CREATE 2006 [11] & $11.0-12.5$ & $13.0-15.0$ & $10.5-11.5$ & Not reported & Not reported \\
\hline Macdougall et al., 2007 [32] & $11.0 \pm 0.5$ & $11.0 \pm 1$ & $\begin{array}{l}\text { Unless } \mathrm{Hb}<9.0-\text { for } \\
\text { maintaining } \mathrm{Hb} \text { level } \\
\text { at } 11.0 \pm 1\end{array}$ & Not reported & Not reported \\
\hline ACORD 2007 [33] & Not reported & $13.0-15.0$ & $10.5-11.5$ & $13.0-15.0$ & $>10.5-11.5$ \\
\hline Cianciaruso et al., 2008 [34] & $11.6 \pm 0.7$ & $12.0-14.0 \pm 0.5$ & Unless $\mathrm{Hb}<9.0$ & $\begin{array}{l}\text { Not reported at the } \\
\text { end of the study }\end{array}$ & $\begin{array}{l}\text { Not reported at the } \\
\text { end of the study }\end{array}$ \\
\hline TREAT 2009 [36] & $<11.0$ & $>13.0$ & Unless $\mathrm{Hb} \leq 9.0$ & $12.5(\mathrm{IR}, 12.0-12.8)$ & $10.6(\mathrm{IR}, 9.9-11.3)$ \\
\hline NEPHRODIAB2 2011 [14] & $10.0-12.9$ & $13.0-14.9$ & $11.0-12.9$ & $<12.0$ & $>13.0$ \\
\hline Akizawa et al., 2011 [37] & $<10.0$ & $11.0-13.0$ & $9.0-11.0$ & $\begin{array}{l}\text { Not reported (achieved } \\
\text { target range) }\end{array}$ & Not reported \\
\hline CAPRIT 2012 [15] & $10.5 \pm 0.8$ & $13.0-15.0$ & $10.5-11.5$ & $13.1 \pm 1.7$ & $11.4 \pm 1.0$ \\
\hline
\end{tabular}

Fig. 2. Risk of bias graph available according to recommendations from the cochrane collaboration.

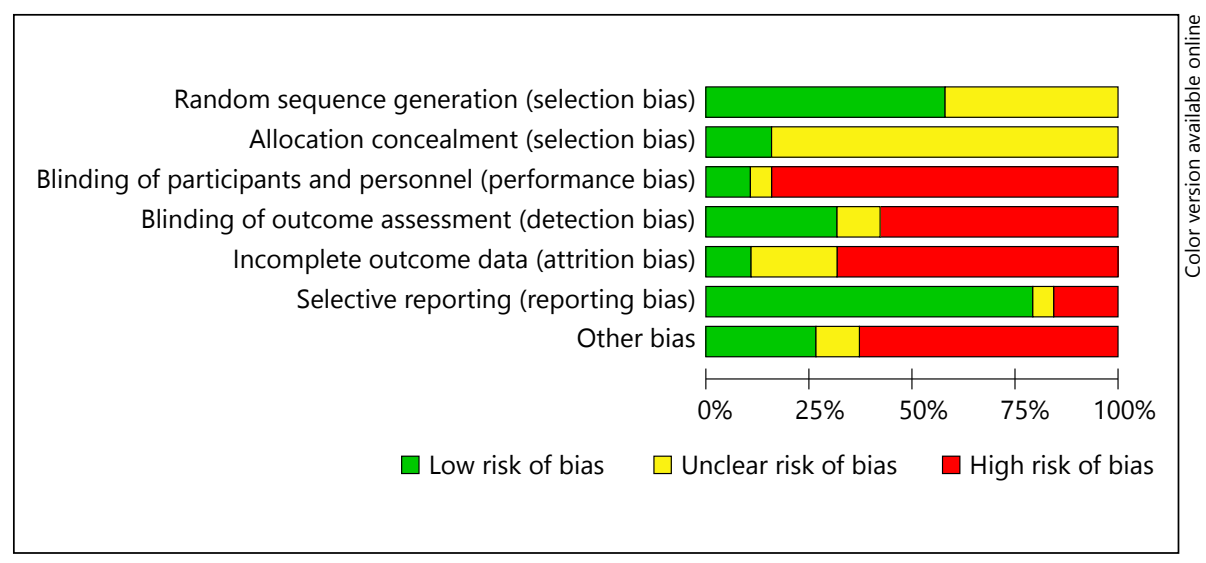




\section{Quantitative Analysis}

Number of Patients Starting RRT during the Study

Period

With regard to the number of patients that required the initiation of RRT during the study, there were no data that would favor either of the two groups (low versus high $\mathrm{Hb}$ target) (17 trials, 8,104 participants, RR 0.97; 95\% CI $0.83-1.15)$. The heterogeneity for this outcome was moderate: $\left(\chi^{2}=28.59, \mathrm{I}^{2}=44 \%\right)$ (fig. 3 , table 3 ).

For the composite outcome all-cause mortality or RRT, there was no statistically significant difference between the high $\mathrm{Hb}$ and the low $\mathrm{Hb}$ arm (17 trials, 8,104 participants, $\mathrm{RR}=0.95 ; 95 \% \mathrm{CI} 0.81-1.12)$; heterogeneity was again moderate $\left(\chi^{2}=38.23, \mathrm{I}^{2}=58 \%\right)$ (fig. 3 ).

Reduction in GFR at the End of the Study. Doubling of Serum Creatinine

Nine studies reported changes in GFR, and did not reveal a significant difference between the two groups (9 trials, 1,828 participants, Mean Difference (MD) -0.45 ; $95 \%$ CI $-2.21-1.31 \mathrm{ml} / \mathrm{min}$ ), although for this outcome measure, the heterogeneity was important $\left(\chi^{2}=302.4\right.$; $\mathrm{I}^{2}=97 \%$ ) (fig. 4, table 3).

Doubling of serum creatinine was reported only by three small studies ( $\mathrm{n}=286$ participants) $[10,15,26]$. There was a statistically significant difference indicating a $47 \%$ reduction in the risk of doubling of the serum creatinine when aiming at higher $\mathrm{Hb}$ values (fig. 3 , table 3$)$.

Serum Creatinine or GFR Value at the End of the Study

There was no difference between the high and the low $\mathrm{Hb}$ target in serum creatinine values or GFR $(\mathrm{ml} / \mathrm{min})$ at the end of the study. This analysis included four studies for the creatinine outcome and 8 studies for the GFR outcome (fig. 4); an important heterogeneity was found for both outcomes $\left(\chi^{2}=15.29 ; \mathrm{I}^{2}=80 \%\right.$ and $\chi^{2}=29.90 ; \mathrm{I}^{2}=$ $77 \%)$.

Proteinuria at the End of the Study and Changes in

Proteinuria from Baseline

Proteinuria was reported only by three studies $[14,30$, 33]. One study [33] reported that there was no change in urine protein, a more recent study [14] reported no statistically significant difference between baseline proteinuria and end-of-treatment proteinuria and the oldest one [30] reported the worsening of proteinuria in a dichotomous format with more events in the low Hb group (10 events vs. 4 events, $\mathrm{n}=195$ participants per arm).
Blood Pressure at the End of the Study. Changes in

BP

Targeting for a higher $\mathrm{Hb}$ level was not associated with higher systolic or diastolic BP levels (5 studies; 934 participants; $\mathrm{MD}=1.83$; 95\% CI $-0.79-4.45 \mathrm{~mm} \mathrm{Hg}$ ). Heterogeneity across these 5 studies was moderate $\left(\chi^{2}=\right.$ 9.33; $\left.\mathrm{I}^{2}=57 \%\right)$. However, the CREATE study [11] mostly contributes (32\%) to the overall weight of this analysis (fig. 4).

\section{Adverse Effects}

The number of participants who discontinued the treatment due to adverse events was reported by ten studies as 1,958 participants, and these studies did not reveal any statistically significant difference between the two comparison groups (fig. 3, table 3). Also, there was no difference for the number of patients experiencing at least one adverse event, including one serious event during the intervention period $(\mathrm{RR}=1.01,95 \% \mathrm{CI} 1.00-1.03,8$ studies, 7,108 participants). Heterogeneity was low for both the analyses $\left(\mathrm{I}^{2}=0 \%\right)$.

However, there was an $18 \%$ higher risk of having at least one serious adverse event during the intervention period for higher as compared to lower $\mathrm{Hb}$ targets (6 studies, 6,268 participants, RR 1.18, 95\% CI 1.01-1.07).

Finally, the risk of having at least one hospitalization during the intervention period was $11 \%$ higher in the higher-Hb target ( 3 studies, 1,910 participants, $\mathrm{RR}=1.11$, $95 \%$ CI 1.00-1.23; $\mathrm{I}^{2}=0 \%$ ) (fig. 3).

\section{Investigation for Sources of Heterogeneity}

Heterogeneity in the effects of lower or higher $\mathrm{Hb}$ targets on renal function at the end of treatment (end of study GFR and change in GFR from baseline) was explored through sub-group analyses based on the type of ESA used (erythropoietin alpha, erythropoietin beta, darbopoetin alpha or undefined ESA), number of participants (less or more than 100) and study duration (less or more than 12 weeks) (online suppl. fig. 1). Causes of heterogeneity were not explored for the serum creatinine outcome since few studies looked at this endpoint. The analysis showed that the type of treatment, number of participants and length of follow-up did not change the effects of anemia corrections at different $\mathrm{Hb}$ targets on renal function. In addition, a subgroup sensitivity analysis, with or without data available from the TREAT 2009 trial [35] (fig. 3) and with or without data available from the CAPRIT trial [15] (transplanted patients), was performed for all dichotomous and continuous outcomes that included this study in the analysis (online suppl. fig. 2 


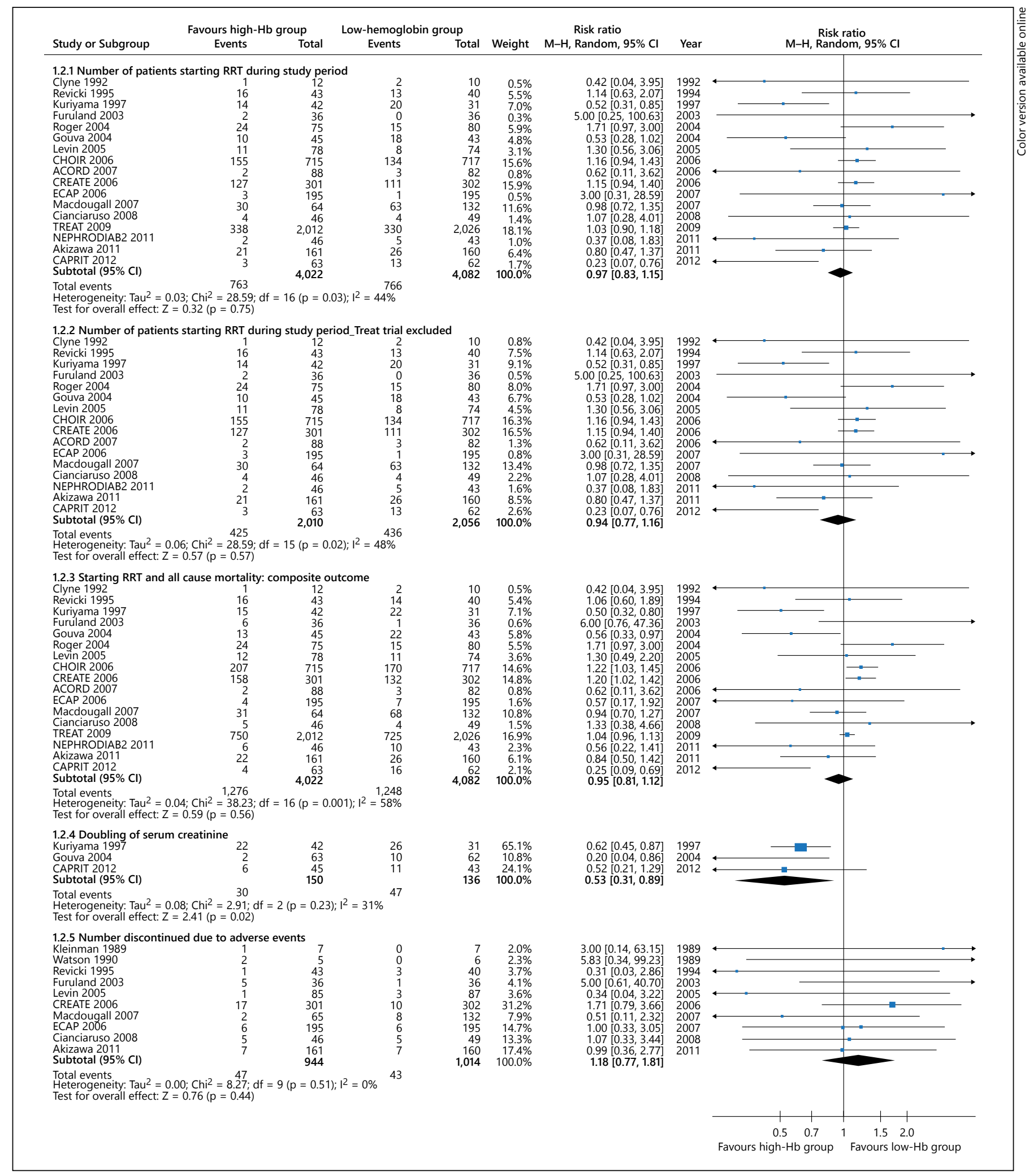

Fig. 3. Effect of high $\mathrm{Hb}$ target versus low $\mathrm{Hb}$ target on dichotomous outcomes: 1.2.1 number of patients starting RRT during study period. 1.2.2 number of patients starting RRT during study period_TREAT trial excluded. 1.2.3 number of patients starting RRT and allcause mortality: composite outcome. 1.2.4 doubling of serum creatinine. 1.2.5 number discontinued due to adverse events. 


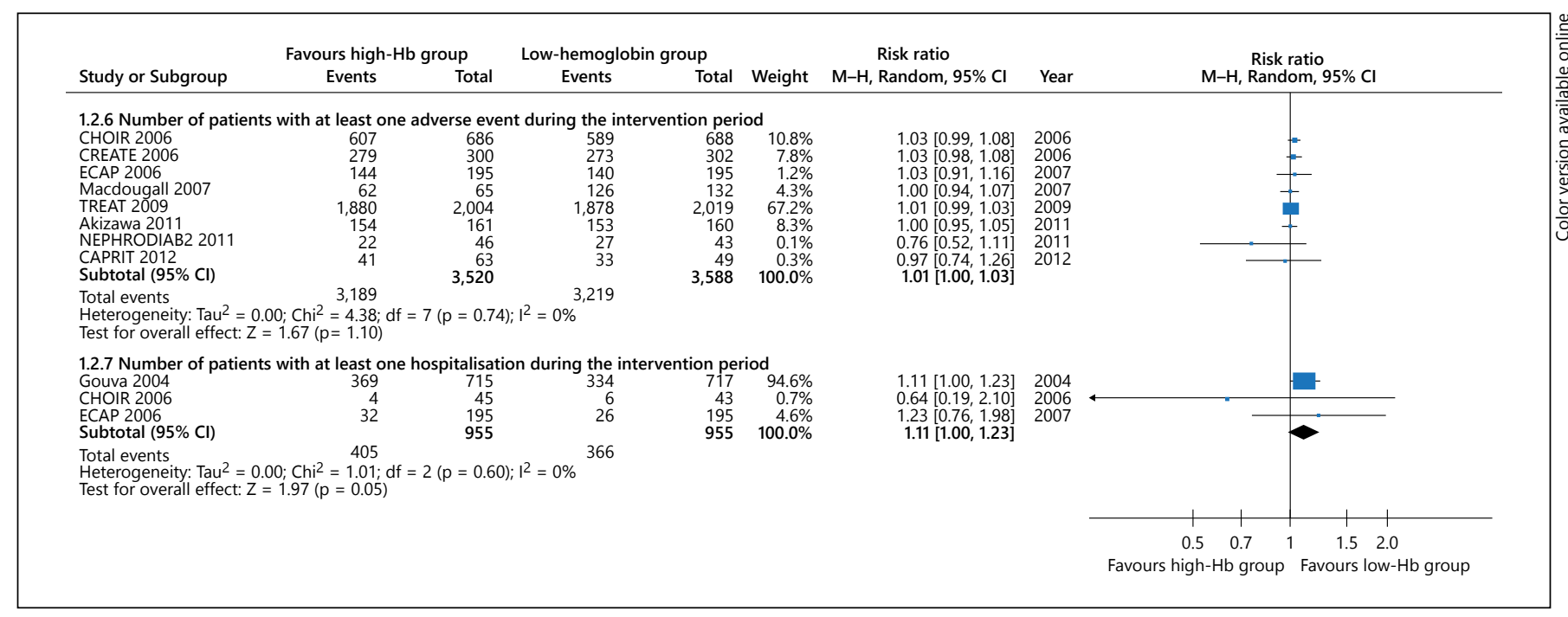

Fig. 3. Effect of high $\mathrm{Hb}$ target versus low $\mathrm{Hb}$ target on dichotomous outcomes: 1.2.6 number of patients with at least one adverse event during the intervention period. 1.2.7 number of patients with at least one hospitalization during the intervention period.

Table 3. Summary of findings

\begin{tabular}{|c|c|c|c|c|c|c|}
\hline Outcome & $\begin{array}{l}\text { Trials reporting } \\
\text { more than one } \\
\text { event/total number } \\
\text { of trials included in } \\
\text { the outcome }\end{array}$ & $\begin{array}{l}\text { Number of } \\
\text { patients } \\
\text { included in } \\
\text { the outcome }\end{array}$ & $\begin{array}{l}\text { Relative } \\
\text { effect }\end{array}$ & $95 \% \mathrm{CI}$ & $\begin{array}{l}\text { Median } \\
\text { treatment } \\
\text { duration, } \\
\text { months }\end{array}$ & $\begin{array}{l}\text { Quality of } \\
\text { evidence* }\end{array}$ \\
\hline Number of patients starting RRT during study period & $17 / 17$ & 8,104 & 0.97 & $(0.83,1.15)$ & 18.41 & Moderate \\
\hline Doubling of serum creatinine & $3 / 3$ & 286 & 0.53 & $(0.31,0.89)$ & 18.5 & Very low \\
\hline
\end{tabular}

* Definition of quality of evidence: High quality = additional research is very unlikely to change our confidence in the estimates of effect; Moderate quality = additional research is likely to have an important impact on our confidence in the estimate of effect; Low quality = additional research is very likely to have an important impact on our confidence in the estimate of effect and is likely to change the estimate; Very low quality = any estimate of the effect is very uncertain.

and 3) showing roughly the same effect. For the TREAT [35] subgroup sensitivity analysis, the analysis performed without the inclusion of this trial did not reveal significant effects estimates differences (with TREAT, effect estimates: $0.97(0.83,1.15)$ and without TREAT: $0.94(0.77$, 1.16)) (fig. 3). As new data regarding a higher prevalence of resistance to ESA treatment in US-CKD patients compared to non-US patients has been recently hypothesized [38], a geographical-subgroup sensitivity analysis was conducted for the adverse events outcome including a comparison of relative effect and heterogeneity with studies comprising US participants versus studies with only
non-US participants. There were no significant effect estimates or heterogeneity differences found (online suppl. fig. 4).

\section{Discussion}

\section{Key Findings}

Our analysis included 19 studies, enrolling 8,129 participants with CKD stages $1-4$. There was no difference in risks for end-stage kidney disease, reduction in GFR, serum creatinine or GFR $(\mathrm{ml} / \mathrm{min})$ values, or in protein- 


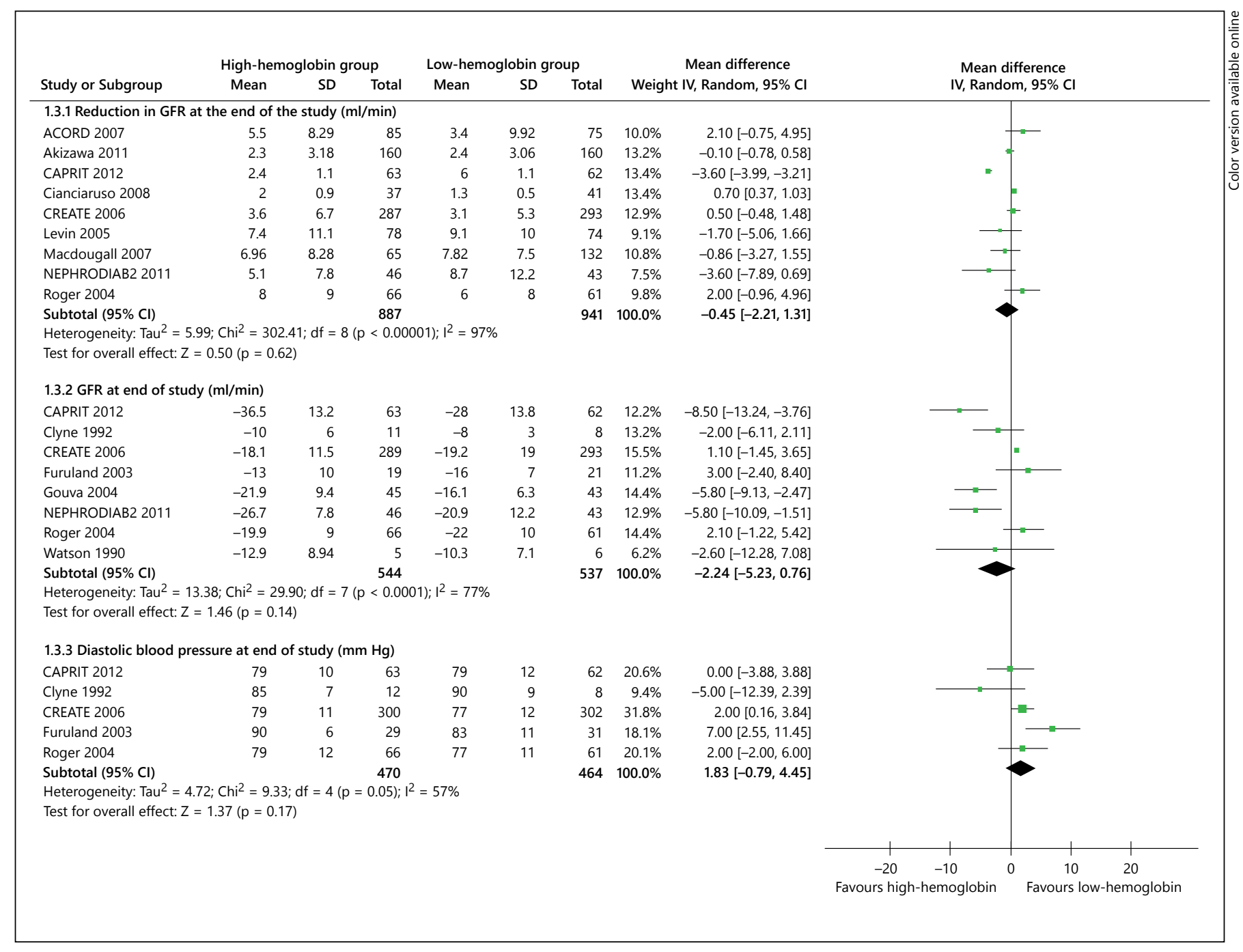

Fig. 4. Effect of high $\mathrm{Hb}$ target versus low $\mathrm{Hb}$ target on continuous outcomes: 1.3.1 reduction in GFR at the end of the study (ml/min). 1.3.2 GFR at end of study $(\mathrm{ml} / \mathrm{min})$. 1.3.3 diastolic blood pressure at end of the study $(\mathrm{mm} \mathrm{Hg})$.

uria, at the end of the study periods when aiming at higher hemoglobin $(\mathrm{Hb})$ targets. Furthermore, no statistically significant differences in a composite outcome need for RRT plus mortality (Risk Ratio [RR] 0.95 [CI 0.81-1.12], 17 trials, $\mathrm{n}=8,104$ patients) were observed. Withdrawal of treatment due to adverse events was similar, as well as the general control of BP, between high and low $\mathrm{Hb}$ targets cohorts of patients.

Some important shortcomings in the manner of reporting outcomes deserve mentioning. Only four studies out of 19 had renal endpoints as primary outcomes; the remaining studies only described these events as secondary outcomes. The studies did not generally feature or recruit from 'rapidly-progressing' $\mathrm{CKD}$ cohorts. The overall quality of the investigational and trial design approaches used to address this key end-point was suboptimal. Finally, data on proteinuria were reported only by three studies.

Two rather different studies included in our metaanalysis seemed to show protective outcomes for the deployment of ESAs in CKD. These were the studies by Gouva et al. (2004) [10] and the more recent CAPRIT study from 2012 [15].

The Gouva study was one of the smallest ones $(n=88)$ of the 19 included in the meta-analysis, and was focused on non-diabetic patients with a wide range of serum creatinine concentrations $(2-6 \mathrm{mg} / \mathrm{dl})$ and mild-to-moderate anemia $(\mathrm{Hb} 9-11 \mathrm{~g} / \mathrm{dl})$, from 14 clinical centers in 
Greece. It was non-blinded, the intervention being early versus later use of ESA. To be eligible for inclusion, patients also had to have stopped all ACEI and/or ARBs for 2 months, and to have controlled BP on non-ACE/ARB therapy. These stringent, unusual, selection criteria make it very challenging to extrapolate the findings of this study, since a large proportion of current $\mathrm{CKD}$ patients are on ACE/ARB-based drug therapy for BP control and proteinuria reduction. During follow-up, 13 (3 deaths) versus 23 ( 4 deaths) patients reached the end point of doubling of creatinine, renal replacement, or death, in the early versus deferred treatment arms, respectively. Thus, the difference between the two arms was largely caused by the initiation of renal replacement (a notoriously subjective, symptom-led, judgment).

The CAPRIT study [15] was a two-year, open-label trial involving 125 post-renal transplant patients. Beside the well-known multifactorial pathogenesis of post-renal transplant anemia (including the presence of immunosuppressive therapy and the altered inflammatory environment), the most notable anemia risk factor still remains and that is the loss of renal allograft function [39]. This is consistent with the loss of endogenous EPO production in CKD patients. The findings of the CAPRIT trial suggested improved allograft survival among patients treated to a higher $\mathrm{Hb}$ level.

Indeed, in the CAPRIT, the patient admixture and comorbidity were highly different from those seen in other anemia studies: $<5 \%$ of subjects having primary diabetes, and only around $15 \%$ subjects with prior cardiovascular history. Adverse event rates were very low compared to CREATE [11], CHOIR [31] and TREAT [35] studies. Additionally, there was little or no information on iron status, or on its therapeutic usage. The ESA dose used, 4,000-6,000 IU Epoetin weekly, was about half to a third seen in the other trials.

Most importantly, there was neither presumption nor demonstration of declining renal function at study entry; no renal biopsy information was obtained to differentiate the immunologically driven loss of GFR from many other potential causes, and no direct measurements of GFR were undertaken. Patient entry back onto dialysis was inevitably partly subjective, and symptom-based, and so with higher $\mathrm{Hb}$ values was intrinsically less likely to happen.

\section{Comparison to Other Studies}

It was our intention to assess the evidence culled from publications until 2014 date range. The first comparison should be done with two early systematic reviews [40,41], published in 2004, although the evidence was quite limited, 4 trials including 77 patients in one meta-analysis and 5 trials with 207 patients in the second. Nevertheless, both meta-analyses showed no difference between $\mathrm{Hb}$ groups regarding the renal progression outcome.

The most meaningful comparison should probably be made with a 2010 meta-analysis by Palmer et al. [12] that evaluated the effects of ESA in CKD patients. Our work has in addition three subsequent published studies included. Most importantly, our main aim was to focus on assessing different renal outcomes, which were not the main output focus of the Palmer paper, whose principal objective was a cardiovascular event/mortality analysis.

\section{Strengths and Limitations}

Our review has a number of strengths and limitations. Strengths include a systematic search of medical databases, data extraction and analysis, and trial quality assessment by two independent reviewers. We also carefully analyzed the most important potential renal end-points including loss of renal function, and dialysis initiation. This has not been done before. Another strength of our review was a detailed examination of trials quality and heterogeneity. The major limitation is the lack of longterm studies analyzing the efficacy of ESA on mortality, progression of $\mathrm{CKD}$, and entry onto dialysis. Another limitation is the populations included in the 19 studies, and how many of them were truly demonstrating progressive loss of GFR prior to enrollment. The majority of the included studies enrolled a relatively small number of patients; they were powered to observe differences in surrogate end-points rather than patient-focused outcomes, and used nonoptimal measures of renal function change over time. Also, in our aim to study ESA role in CKD progression, our search found limited data for all proposed outcomes. The absence of data for some relevant outcomes (e.g., doubling of serum creatinine) might represent an open pathway for future research. In addition, the preponderance of high risk of bias regarding the lack of blinding could be considered a possible limitation.

\section{Implications for Practice}

In CKD patients with anemia, the current KDIGO [42] and ERBP guidelines [43] suggest that a careful exploration of the risk-benefit relationship between $\mathrm{Hb}$, ESAs, and outcomes, should be undertaken for all patients. In some cases, it is expected that clinically relevant benefits of using ESAs to raise $\mathrm{Hb}$ will be seen, but not in all cases, while there are definite risks associated 
with active therapy. However, in the quest for 'nephroprotection' to prevent progressive loss of renal function and the eventual need for dialysis, adjusting the patient's $\mathrm{Hb}$ concentration using ESAs does not seem, from our evidence, to have a compelling logic to support it.

\section{Acknowledgements}

None to declare.

\section{Disclosure Statements}

Adrian Covic received speaker honoraria from Amgen, Roche, Fresenius Medical Care and Abbott, and is a member of the European Renal Best Practices Board.

David Goldsmith received speaker honoraria from Roche, Amgen, Vifor, Takeda, Sandoz.

\section{Role of Funding Source}

No funding source was available for this study.

\section{References}

1 Collins AJ, et al: 'United States Renal Data System 2011 Annual Data Report: atlas of chronic kidney disease and end-stage renal disease in the United States. Am J Kidney Dis 2012;59(1 suppl 1):A7, e1-e420.

$\checkmark 2$ Go AS, et al: Chronic kidney disease and the risks of death, cardiovascular events, and hospitalization. N Engl J Med 2004;351:12961305.

-3 Kerr M, et al: Estimating the financial cost of chronic kidney disease to the NHS in England. Nephrol Dial Transplant 2012;27(suppl 3): iii73-iii80.

4 Fried LF, et al: Kidney function as a predictor of noncardiovascular mortality. J Am Soc Nephrol 2005;16:3728-3735.

5 Iff S, et al: Reduced estimated GFR and cancer mortality. Am J Kidney Dis 2014;63:23-30.

6 Casas JP, et al: Effect of inhibitors of the reninangiotensin system and other antihypertensive drugs on renal outcomes: systematic review and meta-analysis. Lancet 2005;366: 2026-2033.

7 Strippoli GF, et al: Angiotensin converting enzyme inhibitors and angiotensin II receptor antagonists for preventing the progression of diabetic kidney disease. Cochrane Database Syst Rev 2006;4:Cd006257.

8 Gansevoort RT, et al: Chronic kidney disease and cardiovascular risk: epidemiology, mechanisms, and prevention. Lancet 2013;382: 339-352.

9 Jha V, et al: Chronic kidney disease: global dimension and perspectives. Lancet 2013;382: 260-272.

10 Gouva C, et al: Treating anemia early in renal failure patients slows the decline of renal function: a randomized controlled trial. Kidney Int 2004;66:753-760.

-11 Drueke TB, et al: Normalization of hemoglobin level in patients with chronic kidney disease and anemia. N Engl J Med 2006;355: 2071-2084.

12 Palmer SC, et al: Meta-analysis: erythropoiesis-stimulating agents in patients with chronic kidney disease. Ann Intern Med 2010;153: 23-33.
13 Tsubakihara Y, et al: High target hemoglobin with erythropoiesis-stimulating agents has advantages in the renal function of non-dialysis chronic kidney disease patients. Ther Apher Dial 2012;16:529-540.

14 Villar E, et al: Anemia normalization in patients with type 2 diabetes and chronic kidney disease: results of the NEPHRODIAB2 randomized trial. J Diabetes Complications 2011; 25:237-243.

15 Choukroun G, et al: Correction of postkidney transplant anemia reduces progression of allograft nephropathy. J Am Soc Nephrol 2012; 23:360-368.

16 Centers for Disease Control and Prevention: National Chronic Kidney Disease Fact Sheet: General Information and National Estimates on Chronic Kidney Disease in the United States, GA: U.S. Department of Health and Human Services, CDC, 2010, National Chronic Kidney Disease Fact Sheet 2010.

17 Dalrymple LS, et al: Chronic kidney disease and the risk of end-stage renal disease versus death. J Gen Intern Med 2011;26:379-385.

18 Tonelli M, et al: Chronic kidney disease and mortality risk: a systematic review. J Am Soc Nephrol 2006;17:2034-2047.

19 Higgins JPT, Greeen S (eds): Cochrane Handbook for Systematic Reviews of Interventions Version 5.1.0. The Cochrane Collaboration, 2011. Available from http://www.cochranehandbook.org.

20 Higgins JP, et al: Measuring inconsistency in meta-analyses. BMJ 2003;327:557-560.

21 Thompson SG, Sharp SJ: Explaining heterogeneity in meta-analysis: a comparison of methods. Stat Med 1999;18:2693-2708.

22 Kleinman KS, et al: The use of recombinant human erythropoietin in the correction of anemia in predialysis patients and its effect on renal function: a double-blind, placebo-controlled trial. Am J Kidney Dis 1989;14:486495.

23 Watson AJ, et al: Treatment of the anemia of chronic renal failure with subcutaneous recombinant human erythropoietin. Am J Med 1990;89:432-435.
24 Clyne N, Jogestrand T: Effect of erythropoietin treatment on physical exercise capacity and on renal function in predialytic uremic patients. Nephron 1992;60:390-396.

$\checkmark 25$ Revicki DA, et al: Health-related quality of life associated with recombinant human erythropoietin therapy for predialysis chronic renal disease patients. Am J Kidney Dis 1995;25: 548-554.

26 Kuriyama S, et al: Reversal of anemia by erythropoietin therapy retards the progression of chronic renal failure, especially in nondiabetic patients. Nephron 1997;77:176185.

27 Furuland H, et al: A randomized controlled trial of haemoglobin normalization with epoetin alfa in pre-dialysis and dialysis patients. Nephrol Dial Transplant 2003;18: 353-361.

28 Roger SD: Effects of early and late intervention with epoetin on left ventricular mass among patients with chronic kidney disease (stage 3 or 4): results of a randomized clinical trial. J Am Soc Nephrol 2004;15:148-156.

29 Levin A, et al: Canadian randomized trial of hemoglobin maintenance to prevent or delay left ventricular mass growth in patients with CKD. Am J Kidney Dis 2005;46:799-811.

30 Rossert J, et al: Effect of early correction of anemia on the progression of CKD. Am J Kidney Dis 2006;47:738-750.

31 Singh AK, et al: Correction of anemia with epoetin alfa in chronic kidney disease [see comment]. N Engl J Med 2006;355:20852098.

32 Macdougall IC, Temple RM, Kwan JT: Is early treatment of anaemia with epoetin-alpha beneficial to pre-dialysis chronic kidney disease patients? Results of a multicentre, openlabel, prospective, randomized, comparative group trial. Nephrol Dial Transplant 2007;22: 784-793.

33 Ritz E, et al: Target level for hemoglobin correction in patients with diabetes and $\mathrm{CKD}$ : primary results of the Anemia Correction in Diabetes (ACORD) Study. Am J Kidney Dis 2007;49:194-207. 
34 Cianciaruso B, et al: Italian randomized trial of hemoglobin maintenance to prevent or delay left ventricular hypertrophy in chronic kidney disease. J Nephrol 2008;21:861-870.

35 Pfeffer MA, et al: A trial of darbepoetin alfa in type 2 diabetes and chronic kidney disease. $\mathrm{N}$ Engl J Med 2009;361:2019-2032.

36 KDOQI, KDOQI Clinical Practice Guideline and Clinical Practice Recommendations for anemia in chronic kidney disease: 2007 update of hemoglobin target. Am J Kidney Dis 2007;50:471-530.

37 Akizawa T, et al: Positive outcomes of high hemoglobin target in patients with chronic kidney disease not on dialysis: a randomized controlled study. Ther Apher Dial 2011;15: 431-440.
38 De Nicola L, et al: Responsiveness to erythropoiesis-stimulating agents in chronic kidney disease: does geography matter? Drugs 2014; 74:159-168.

39 Molnar MZ, et al: Prevalence and management of anaemia in renal transplant recipients: data from ten European centres. Nephron Clin Pract 2011;117:c127-c134.

40 Strippoli GF, et al: Hemoglobin targets for the anemia of chronic kidney disease: a metaanalysis of randomized, controlled trials. J Am Soc Nephrol 2004;15:3154-3165.
41 Cody June D, et al: Recombinant human erythropoietin for chronic renal failure anaemia in pre-dialysis patients. Cochrane Database Syst Rev 2005;3. DOI: 10.1002/14651858. CD003266.

42 Drueke TB, Parfrey PS: Summary of the KDIGO guideline on anemia and comment: reading between the (guide)line(s). Kidney Int 2012;82:952-960.

43 Locatelli F, et al: Kidney Disease: Improving Global Outcomes guidelines on anaemia management in chronic kidney disease: a European Renal Best Practice position statement. Nephrol Dial Transplant 2013;28:13461359. 